\title{
Corrigendum: Human Tau Expression Does Not Induce Mouse Retina Neurodegeneration, Suggesting Differential Toxicity of Tau in Brain vs. Retinal Neurons
}

\author{
Léa Rodriguez ${ }^{1,2}$, Julius Baya Mdzomba ${ }^{1,2}$, Sandrine Joly ${ }^{1,2}$, Mélissa Boudreau-Laprise ${ }^{1,2}$, \\ Emmanuel Planel ${ }^{3,4}$ and Vincent Pernet ${ }^{1,2 *}$ \\ ${ }^{1}$ CUO-Recherche, Centre de Recherche du CHU de Québec, Quebec, QC, Canada, ${ }^{2}$ Département d'ophtalmologie, \\ Faculté de Médecine, Université Laval, Quebec, QC, Canada, ${ }^{3}$ Axe Neurosciences, Centre de Recherche du CHU de \\ Québec, Quebec, QC, Canada, ' Département de Psychiatrie et de Neurosciences, Faculté de Médecine, Université Laval, \\ Quebec, QC, Canada
}

Keywords: human Tau, Alzheimer's disease, retina, electroretinogram, photoreceptors, bipolar cells, mTOR

\section{OPEN ACCESS}

Edited and reviewed by: David Blum,

INSERM U1172 Centre de Recherche Jean Pierre Aubert, France

*Correspondence: Vincent Pernet vincent.pernet.1@ulaval.ca; vincent.pernet@yahoo.ca

Received: 17 September 2018 Accepted: 04 October 2018 Published: 24 October 2018

Citation: Rodriguez L, Mdzomba JB, Joly S, Boudreau-Laprise M, Planel E and Pernet V (2018) Corrigendum: Human

Tau Expression Does Not Induce Mouse Retina Neurodegeneration,

Suggesting Differential Toxicity of Tau in Brain vs. Retinal Neurons.

Front. Mol. Neurosci. 11:390

doi: 10.3389/fnmol.2018.00390

\section{A Corrigendum on}

Human Tau Expression Does Not Induce Mouse Retina Neurodegeneration, Suggesting Differential Toxicity of Tau in Brain vs. Retinal Neurons

by Rodriguez, L., Mdzomba, J. B., Joly, S., Boudreau-Laprise, M., Planel, E., and Pernet, V. (2018). Front. Mol. Neurosci. 11:293. doi: 10.3389/fnmol.2018.00293

In the original article, the reference for (Leinonen et al., 2016) was incorrectly written as Leinonen, H., Keksa-Goldsteine, V., Ragauskas, S., Kohlmann, P., Singh, Y., Savchenko, E., et al. (2017). Retinal Degeneration in a mouse model of CLN5 disease is associated with compromised autophagy. Sci. Rep. 7:1597. doi: 10.1038/s41598-017-01716-1.

It should be Leinonen, H., Lipponen, A., Gurevicius, K., and Tanila, H. (2016). Normal amplitude of electroretinography and visual evoked potential responses in A $\beta \mathrm{PP} / \mathrm{PS} 1$ mice. $J$. Alzheimers Dis. 51, 21-26. doi: 10.3233/JAD-150798.

The authors apologize for this error and state that this does not change the scientific conclusions of the article in any way. The original article has been updated.

\section{REFERENCES}

\footnotetext{
Leinonen, H., Lipponen, A., Gurevicius, K., and Tanila, H. (2016). Normal amplitude of electroretinography and visual evoked potential responses in AßPP/PS1 mice. J. Alzheimers Dis. 51, 21-26. doi: 10.3233/JAD-150798
}

Conflict of Interest Statement: The authors declare that the research was conducted in the absence of any commercial or financial relationships that could be construed as a potential conflict of interest.

Copyright () 2018 Rodriguez, Mdzomba, Joly, Boudreau-Laprise, Planel and Pernet. This is an open-access article distributed under the terms of the Creative Commons Attribution License (CC BY). The use, distribution or reproduction in other forums is permitted, provided the original author(s) and the copyright owner(s) are credited and that the original publication in this journal is cited, in accordance with accepted academic practice. No use, distribution or reproduction is permitted which does not comply with these terms. 